\title{
Odorless inhalant toxic encephalopathy in developing countries household: Gas geyser syndrome
}

Anish Mehta, Rohan Mahale, Aju Abraham John, Masoom Mirza Abbas, Mahendra Javali, Purushottam Acharya, Srinivasa Rangasetty

Department of Neurology, MS Ramaiah Medical College and Hospital, Bengaluru, Karnataka, India

\begin{abstract}
Background: Liquefied petroleum gas geysers are used very frequently for heating water in developing countries such as India. However, these gas geysers emit various toxic gases; one among them is colorless, odorless carbon monoxide (CO). In the past few years, there were reports of unexplained loss of consciousness in the bathroom. However, the exact cause for these episodes has been recognized as toxic encephalopathy due to toxic gases inhalation mainly CO. Objective: To analyze the clinical profile and outcome of patients brought with loss of consciousness in the bathroom while bathing using gas geyser. Materials and Methods: Case records of patients with the diagnosis of gas geyser syndrome from 2013 to 2015 were retrieved and analyzed. Twenty-four cases were identified and included in the study. This was a retrospective, descriptive study. Results: Twenty-four patients were brought to our Emergency Department with loss of consciousness in the bathroom while bathing. Twenty-one cases had loss of consciousness during bathing and recovered spontaneously. Two cases were found dead in the bathroom and were brought to the Department of Forensic Medicine for postmortem. One case was brought in deep altered state of consciousness and succumbed to illness within 1 week. Conclusion: Awareness regarding CO intoxication due to usage of ill-fitted, ill-ventilated gas geyser is necessary as they are entirely preventable conditions.
\end{abstract}

Key words: Carbon monoxide, gas geyser, liquefied petroleum gas, toxic encephalopathy

\section{Introduction}

Liquefied petroleum gas (LPG) geysers are used very frequently for heating water in developing countries such as India. These geysers are simple, economical in the form of faster heating of water and are used in bathrooms for bathing purpose. The electrical supply is erratic in developing countries; as a result, cheaper modes such as gas geyser for heating water for bathing are utilized. ${ }^{[1]}$ However, these gas geysers emit various

\section{Address for correspondence:}

Dr. Anish Mehta, Department of Neurology, MS Ramaiah Medical

College and Hospital, Bengaluru - 560 054, Karnataka, India.

E-mail: anishmehta1302@gmail.com

\begin{tabular}{|l|l|}
\hline \multicolumn{2}{|c|}{ Access this article online } \\
\hline Quick Response Code: & Website: \\
\hline & www.ruralneuropractice.com \\
\cline { 2 - 3 } & \\
\hline
\end{tabular}

toxic gases; one among them is colorless, odorless carbon monoxide (CO). In the past few years, there were reports of unexplained loss of consciousness in the bathroom. Users in most of the cases recovered spontaneously with few having life-threatening after effects. These episodes were attributed to seizures as hot water epilepsy, head injury, stroke, cardiac events, and vasovagal syncopal episodes. ${ }^{[2]}$ However, the exact cause for these episodes has been recognized as toxic encephalopathy due to toxic gases inhalation, mainly $\mathrm{CO}$. The need for awareness of gas geyser syndrome is necessary to prevent fatalities. Here, we describe the patients brought to our Emergency Department with loss of consciousness in the bathroom while bathing over a period of 2 years.

This is an open access article distributed under the terms of the Creative Commons Attribution-NonCommercial-ShareAlike 3.0 License, which allows others to remix, tweak, and build upon the work non-commercially, as long as the author is credited and the new creations are licensed under the identical terms.

For reprints contact: reprints@medknow.com

How to cite this article: Mehta A, Mahale R, John AA, Abbas MM, Javali $\mathrm{M}$, Acharya $\mathrm{P}$, et al. Odorless inhalant toxic encephalopathy in developing countries household: Gas geyser syndrome. J Neurosci Rural Pract 2016;7:228-31. 


\section{Materials and Methods}

Case records of patients with the diagnosis of gas geyser syndrome from 2013 to 2015 were retrieved and analyzed. Twenty-four cases were identified and included in the study. All the patients were evaluated by a neurologist and following details were noted - age, gender distribution, demographic details, details about gas geyser installation and bathroom ventilation, clinical presentation and course in the hospital, details about neuroimaging and electroencephalography (EEG) findings, and outcome.

\section{Results}

We found 24 cases during the study period. There were 7 males and 17 females in the age group of 17-45 years. Twenty cases were from urban areas living in Bengaluru. Four cases were from a rural setting. Twenty-one cases had loss of consciousness during bathing and recovered spontaneously. Two cases were found dead in the bathroom and were brought to the Department of Forensic Medicine for postmortem. One case was brought in deep altered state of consciousness and succumbed to illness within 1 week. None of the cases had a history of seizure, stroke, head injury, and cardiovascular risk factor for syncope. Magnetic resonance imaging (MRI) brain of 21 cases with loss of consciousness and spontaneous recovery showed no abnormalities. The case with deep altered state of consciousness during admission had MRI abnormalities suggestive of hypoxic brain insult. EEG did not reveal any abnormalities except diffuse slowing of background rhythm in one patient who was critically ill. The salient clinical, radiological, and EEG characteristics of each patient have been summarized in Table 1 .

\section{Case 1}

A 26-year-old woman had a fall while bathing with hot water. When she did not come out from the bathroom for nearly $1 \mathrm{~h}$, her family members became suspicious and broke open the door. She was found unconscious naked. There was no froth from the mouth. She was rushed to hospital where she gradually regained consciousness over the next $1 \mathrm{~h}$. On examination, there was no tongue bite. Her vitals were stable. There was no evidence of any neurological deficit. Her MRI brain was normal. All routine blood tests including serum creatine phosphokinase and EEG were normal. She was diagnosed as hot water epilepsy and advised to take prophylaxis with clobazam during head bath. Five days later, she was brought by family members with similar complaints. On detailed history regarding usage of gas geyser revealed that they were using gas geyser that was located completely (with burner and cylinder) inside the small-sized bathroom. A diagnosis of possible $\mathrm{CO}$ intoxication was made and was advised to use gas geyser in a well-ventilated bathroom.

\section{Case 2}

A17-year-old girl was found unconscious in the bathroom while bathing. She was taken to local hospital, and a diagnosis of seizure was made. She was started on injectable antiepileptic drugs and referred to our hospital for further management. On examination, the heart rate was 130 beats/min; blood pressure was 100/68 $\mathrm{mmHg}$, and respiratory rate was $20 / \mathrm{min}$. There were injury marks on the back but no marks of ligature around the neck. Neurologically, she was deeply comatose with decerebrate posturing to painful stimulus. Pupils were mid-dilated, with sluggish reaction to light. All deep tendon reflexes were sluggish, and both plantar responses were extensor. Complete hemogram, renal, liver, and thyroid function tests, and serum electrolytes were normal. Arterial blood gas analysis showed metabolic acidosis (corrected). Electrocardiogram revealed sinus tachycardia. Blood screening for toxic substances was negative. Computed tomography of the brain showed loss of gray-white matter differentiation with hyperdense basal ganglia and cerebellum suggestive of hypoxic brain insult [Figure 1]. EEG showed diffuse slowing of background rhythm suggestive of diffuse brain dysfunction. A provisional diagnosis of toxic/hypoxic encephalopathy was made. She was started on anti-edema measures with neuroprotective agents. Within 7 days, she succumbed to her illness. It was found that she was the first to take bath that day and had taken longer time for bathing in a gas geyser-fitted bathroom with ill-ventilation. The blood sample was sent for $\mathrm{CO}$ level estimation but was negative.

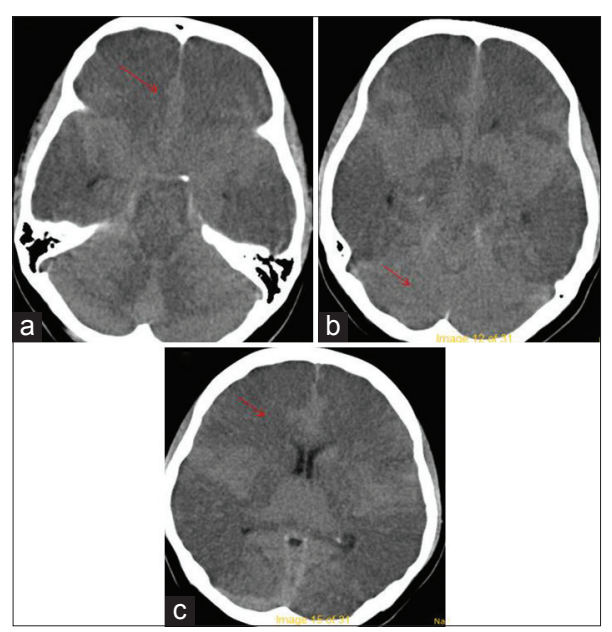

Figure 1: Computed tomography brain images (a-c) shows loss of graywhite matter differentiation with hyperdense cerebellum (red arrows) 
Table 1: Clinical, radiological and EEG characteristics of patients

\begin{tabular}{|c|c|c|c|c|c|c|c|c|}
\hline $\begin{array}{l}\text { Subject } \\
(n)\end{array}$ & $\begin{array}{c}\text { Age } \\
\text { (years) }\end{array}$ & $\begin{array}{c}\text { Sex: } \\
\text { female }(F) / \\
\text { male }(M)\end{array}$ & Clinical features (C/F) & $\begin{array}{l}\text { Neurolo-gical } \\
\text { Examination }\end{array}$ & $\begin{array}{l}\mathbf{C T} \\
\text { brain } \\
\text { (plain) }\end{array}$ & $\begin{array}{l}\text { MRI brain } \\
\text { (plain) } \\
\text { and Angio }\end{array}$ & EEG & Prognosis \\
\hline 1 & 22 & $\mathrm{~F}$ & 1 episode of LOC & Normal & Normal & Normal & Normal & recovered \\
\hline 2 & 26 & $\mathrm{~F}$ & Giddiness and 1 episode of LOC & Normal & Normal & Normal & Normal & recovered \\
\hline 3 & 17 & $\mathrm{~F}$ & LOC and 3 episodes of seizures and coma & GCS (4/15) & $\begin{array}{l}\text { Cerebral } \\
\text { Odema } \\
\text { with HIE }\end{array}$ & - & $\begin{array}{l}\text { Diffuse } \\
\text { background } \\
\text { slowing }\end{array}$ & Death \\
\hline 4 & 22 & $\mathrm{~F}$ & 1 episode of LOC & Normal & Normal & Normal & Normal & Recovered \\
\hline 5 & 40 & $\mathrm{~F}$ & 1 episode of LOC and headache & Normal & Normal & Normal & Normal & Recovered \\
\hline 6 & 28 & $\mathrm{~F}$ & 1 episode of LOC & $\operatorname{GCS}(3 / 15)$ & - & - & - & Death \\
\hline 7 & 29 & $\mathrm{~F}$ & 1 episode of LOC and headache & Normal & Normal & Normal & Normal & Recovered \\
\hline 8 & 42 & $\mathrm{~F}$ & 1 episode of LOC and confusion & Normal & Normal & Normal & Normal & Recovered \\
\hline 9 & 14 & $\mathrm{~F}$ & Giddiness and 1 episode of LOC & Normal & Normal & Normal & Normal & Recovered \\
\hline 10 & 25 & $\mathrm{~F}$ & 1 episode of LOC & $\operatorname{GCS}(3 / 15)$ & - & - & - & Death \\
\hline 11 & 21 & $\mathrm{~F}$ & 1 episode of LOC & $\operatorname{GCS}(3 / 15)$ & - & - & - & death \\
\hline 12 & 34 & $\mathrm{~F}$ & 1 episode of LOC , headache and vomiting & Normal & Normal & Normal & Normal & Recovered \\
\hline 13 & 18 & $\mathrm{~F}$ & 1 episode of LOC, Headache & Normal & Normal & Normal & Normal & Recovered \\
\hline 14 & 33 & $\mathrm{~F}$ & Giddiness headache 1 episode of LOC & Normal & Normal & Normal & Normal & Recovered \\
\hline 15 & 45 & $\mathrm{~F}$ & Headache and 1 episode of LOC & Normal & Normal & - & Normal & Recovered \\
\hline 16 & 20 & $\mathrm{~F}$ & 1 episode of LOC & Normal & Normal & Normal & Normal & Recovered \\
\hline 17 & 29 & $\mathrm{~F}$ & 1 episode of LOC & Normal & Normal & Normal & Normal & Recovered \\
\hline 18 & 16 & M & Headache and 1 episode of LOC & Normal & Normal & - & Normal & Recovered \\
\hline 19 & 32 & M & 1 episode of LOC & Normal & Normal & Normal & Normal & Recovered \\
\hline 20 & 28 & M & Giddiness and 1 episode of LOC & Normal & Normal & Normal & Normal & Recovered \\
\hline 21 & 41 & M & 1 episode of LOC & Normal & Normal & Normal & Normal & Recovered \\
\hline 22 & 19 & M & Headache vomiting, 1 episode of LOC & Normal & Normal & Normal & Normal & Recovered \\
\hline 23 & 25 & M & 1 episode of LOC & Normal & Normal & Normal & Normal & Recovered \\
\hline 24 & 29 & M & 1 episode of LOC & Normal & Normal & Normal & Normal & Recovered \\
\hline
\end{tabular}

LOC: Loss of consciousness, GCS: Glasgow coma scale, HIE: Hypoxic ischemic encephalopathy, CT: Computed tomography, MRI: Magnetic resonance imaging, EEG: Electroencephalogram

\section{Discussion}

All the 24 cases were brought to the hospital with history of loss of consciousness while bathing. The common link in all the cases was the usage of gas geyser in a small ill-ventilated bathroom. These events occurred in young- to middle-aged individuals without any significant risk factors. Most of the cases were females as they were supposedly exposed for longer duration to the toxic gases due to longer duration of bathing. All the patients regained normal consciousness with excellent neurological recovery except three cases who succumbed to illness. Levels of cax domestic cooking gas are pressurized LPG in iron tanks. The main composition of LPG is propane and butane (hydrocarbon gases). Other naturally occurring gases such as $\mathrm{CO}$ and methane are also present. Sulfur dioxide is added to produce the pungent smell to ensure quick detection of LPG leakage. When adequate oxygen is present, hydrocarbon gases undergo complete combustion to form water and carbon dioxide. However, when oxygen is inadequate, $\mathrm{CO}$ and nitrogen oxides (including nitric oxide and nitrogen dioxide) are produced instead. Small amounts of CO are produced due to leakage of LPG tank or from partial combustion of the hydrocarbon gases of LPG ${ }^{[3]}$ Defective devices, defective installation, and poor ventilation are the frequent causes for the inadequate oxygen required for the complete combustion of hydrocarbon gases. Gas geysers are preferred to electric geysers as it heats up the water faster, cheaper to operate, and nonrequirement of electricity. There are guidelines developed by regulatory agencies for the use of these geysers, including the use of timers, site of installations and dimensions, and ventilation requirements of the room in which they are fitted.

$\mathrm{CO}$ is a toxic, colorless, and odorless gas, which accumulates rapidly and reaches concentrations, dangerous for humans. It quickly binds to hemoglobin with an affinity 200-250 times higher than that of oxygen to form carboxyhemoglobin ( $\mathrm{COHb}$ ). Hence, there is a decrease in the arterial oxygen content and shift of the oxyhemoglobin dissociation curve to the left causing hypoxia. ${ }^{[2]}$ Much of the tissue damage involves inflammatory changes and white cell activation, with increased capillary leakage and edema. CO has also been shown to impair tissue 
perfusion through myocardial depression and arrhythmias and peripheral vasodilatation. Acute $\mathrm{CO}$ poisoning presents with general malaise, headache, dizziness, and confusion. Coma or seizures can occur in patients with prolonged exposure. ${ }^{[4,5]}$ The classical cherry-red appearance is not seen in all cases of acute poisoning and may not be apparent even in cases of severe toxicity. Symmetrical basal ganglia lesions are one of the radiological abnormalities apparent on MRI. ${ }^{[6]}$ Hyperoxygenation facilitates the production of partially reduced oxygen species, which oxidizes essential proteins and nucleic acids, causing typical reperfusion injury. $\mathrm{CO}$ exposure has been shown to cause lipid peroxidation, leading to reversible demyelination of central nervous system lipids. ${ }^{[7,8]}$ Immediate death is most likely to be due to a lethal arrhythmia, due to cardiac sensitivity to hypoxia and the preferential binding to cardiac myoglobin..$^{[9]}$

There are two main types of gas geysers depending on the type of flue (vent) system. One is flueless or room sealed which is the first choice for new installation, and the other is the external flue. In flueless gas geyser, fresh air for combustion and combustion products are taken from and discharged directly to outside air, without contaminating room air. However, flueless gas geyser is considered dangerous as combustion products containing $\mathrm{CO}$, discharge directly into the room, and may build up to dangerous levels. Various studies have shown that flueless gas geyser emits many combustion products that include nitrogen dioxide, $\mathrm{CO}$, and formaldehyde and are often higher than the stipulated guideline levels, especially when the heaters are operated at low gas pressure. ${ }^{[10]}$ A study in Copenhagen showed that most cases of $\mathrm{CO}$ poisoning from gas water heaters were due to sooted convectors and installed without flue. ${ }^{[11]}$ Study by Correia et al. on gas geyser syndrome from India reported 26 patients with this syndrome ranging from seizure-like episode to $\mathrm{CO}$ intoxication. ${ }^{[1]}$

The effects found in our patients could probably be attributed to LPG combustion and/or CO intoxication as the levels of $\mathrm{COHb}$ levels could not be assessed due to nonavailability. This is the limitation of our study.

\section{Conclusion}

Awareness regarding $\mathrm{CO}$ intoxication due to usage of ill-fitted, ill-ventilated gas geyser is necessary as they are entirely preventable conditions. The clinical features range from mild altered level of consciousness with spontaneous recovery to death. It is also important from medicolegal point of view as most of the patients were female and were found unconscious in the bathroom.

\section{Acknowledgments}

Authors thank Department of Forensic Medicine for their valuable input.

\section{Financial support and sponsorship \\ Nil.}

\section{Conflicts of interest}

There are no conflicts of interest.

\section{References}

1. Correia P, Agrawal C, Ranjan R. Gas geyser syndrome: An important preventable cause of disabling neurological events. Ann Indian Acad Neurol 2013;16:245-8.

2. Singh P, Lamba A, Bansal R, Singh G. Unexplained neurological events during bathing in young people: Possible association with the use of gas geysers. Ann Indian Acad Neurol 2008;11:103-5.

3. Chong CK, Senan P, Kumar GV, Kesihatan P, Kesihatan PP. Carbon monoxide poisoning from gas water heater installed and operated in the bathroom. Med J Malaysia 1997;52:169-71.

4. Mehta SR, Das S, Singh SK. Carbon monoxide poisoning. Med J Armed Forces India 2007;63:362-5.

5. Ely EW, Moorehead B, Haponik EF. Warehouse workers' headache: Emergency evaluation and management of 30 patients with carbon monoxide poisoning. Am J Med 1995;98:145-55.

6. O'Donnell P, Buxton PJ, Pitkin A, Jarvis LJ. The magnetic resonance imaging appearances of the brain in acute carbon monoxide poisoning. Clin Radiol 2000;55:273-80.

7. Ernst A, Zibrak JD. Carbon monoxide poisoning. N Engl J Med 1998;339:1603-8.

8. Weaver LK, Hopkins RO, Chan KJ, Churchill S, Elliott CG, Clemmer TP, et al. Hyperbaric oxygen for acute carbon monoxide poisoning. $\mathrm{N}$ Engl J Med 2002;347:1057-67.

9. Raub JA, Mathieu-Nolf M, Hampson NB, Thom SR. Carbon monoxide poisoning - A public health perspective. Toxicology 2000;145:1-14.

10. Brown SK, Mahoney KJ, Cheng M. Room chamber assessment of the pollutant emission properties of (nominally) low-emission unflued gas heaters. Indoor Air 2004;14 Suppl 8:84-91.

11. Thomsen JL, Kardel T. Intoxication at home due to carbon monoxide production from gas water heaters. Forensic Sci Int 1988;36:69-72. 